\title{
EVALUASI LPLPO (LAPORAN PEMAKAIAN DAN LEMBAR PERMINTAAN OBAT)
}

\author{
Wawang Anwarudin*
}

\begin{abstract}
ABSTRAK
Standar pelayanan kefarmasian di Puskesmas yang bersifat Managerial dimulai dari perencanaan kebutuhan obat, permintaan obat, penerimaan obat, penyimpanan obat, pendistribusian obat serta pencatatan dan pelaporan yang tujuannya untuk menjamin kelangsungan ketersediaan dan keterjangkauan obat yang efektif, efisian dan rasional. Dalam pencatatan dan pelaporan termasuk pembuatan LPLPO merupakan rangkaian kegiatan dalam rangka penatalaksanaan obat baik yang diterima, disimpan dan didistribusikan dan digunakan di Puskesmas atau diunit pelayanan kesehatan lainnya.Tujuan pencatatan pelaporan LPLPO adalah sebagai bukti tertulis bahwa pengelolaan obat telah dilaksanakan sebagai sumber data untuk melakukan pengaturan dan pengendalian serta memberikan penilaian terhadap capaian kinerja pengelolaan obat di Puskesmas.
\end{abstract}

Kata Kunci : Evaluasi, LPLPO

\begin{abstract}
Standard pharmaceutical services in health centers managerial activities are starting from the planning needs of the drug, drug demand, acceptance of drug, drug storage, drug distribution and record keeping and reporting that aim to ensure continuity of availability and affordability of effective drugs, fuel-efficient and rational. In recording and reporting including LPLPO manufacturea series of activities in the framework of the management of both drug sare received, stored and distributed and used in the health center or other health cared unit. Recording purposes LPLPO reporting is as written evidence that drug management has been implemented as a data source to perform the regulation and control as well as providing an assessment of achievement of management performance drugs in health centers.
\end{abstract}

Keywords : Evaluation, LPLPO

\footnotetext{
* Staf Pengajar Akademi Farmasi Muhammadiyah Kuningan
} 


\section{PENDAHULUAN}

Proses pengisian dokumen UPTD puskesmas nomor ekspedisi tanggal pengiriman LPLPO ke Dinas Kesehatan Kabupaten dapat digunakan sebagai data penunjang untuk mengevaluasi ketepatan dalam penyerahan LPLPO ke Dinas Kesehatan yang telah di tetapkan yaitu paling lambat tanggal 5 setiap bulannya. Hal ini penting adanya karena di tingkat Kabupaten harus melaksanakan rekapitulasi laporan LPLPO untuk dilaporkan ke tingkat provinsi paling lambat tanggal 10 setiap bulannya. ${ }^{1}$

Kenyataan di lapangan dari seluruh puskesmas yang ada di Kabupaten Kuningan sebanyak 37 puskesmas hanya kurang lebih 65\% saja yang bisa menyerahkan LPLPO ke Dinas Kesehatan paling lambat tanggal 5 setiap bulannya, sisanya tergolong puskesmas yang lambat dalam penyerahan LPLPO ke Dinas Kesehatan.

Terlambatnya LPLPO ke Dinas Kesehatan diatas tanggal 5 berdasarkan keterangan dan alasan yang didapat dari pengelola penanggungjawab obat puskesmas antara lain :

1. Terlambatnya pelaporan LPLPO sub unit yang diterima oleh Puskesmas yang bersangkutan.

2. Sistim pencatatan dan pelaporan di Puskesmas selalu di tunda-tunda

3. Terlalu banyaknya jenis pelaporan yang harus dikerjakan, termasuk merangkap jabatan selain sebagai penanggungjawab pengelola obat.

4. Sistim pencatatan dan pelaporan obat di Puskesmas masih ada yang belum ditunjang oleh komputerisasi, hanya menggunakan sistem manual.

Penggunaan obat yang berdasarkan resep di Puskesmas drug of choice tidak banyak beragam. Hal ini dikarenakan pelayanan kesehatan kepada masyarakat yang dilaksanakan di tingkat puskesmas merupakan fasilitas pelayanan kesehatan tingkat dasar. Sehingga tidak bisa disamakan dengan fasilitas pelayanan kesehatan tingakat rujukan seperti di Rumah Sakit yang drug of choice nya banyak ragam, dan itu sudah merupakan ketentuan yang diatur dalam peraturan pemerintah dan perundang-undangan. ${ }^{2}$

Hal ini bisa terjadi seperti pengkonsentrasian penggunaan obat pada satu item obat saja, sehingga obat yang lainnya yang mempunyai khasiat sama jarang atau tidak diresepkan, yang pada akhirnya bisa terjadi penumpukan obat yang mengakibatkan obat dapat menjadi kadaluarsa/expire date. ${ }^{2}$

Bila pengkonsentrasian penggunaan obat itu terjadi maka pelaku penulis resep di Puskesmas baik itu dokter, dokter gigi, perawat, atau bidan dianjurkan untuk meresepkan obat yang masih menumpuk agar terhindar dari kejadian expire date, sekaligus untuk pemerataan penggunaan obat.

Berdasarkan hal-hal tersebut di atas maka penulis melakukan penelitian ini untuk mengetahui sistem pencatatan dan pelaporan obat yang baik ditingkat Puskesmas dengan menggunakan format LPLPO (Laporan Penggunaan dan Lembar Permintaan Obat).

\section{METODE PENELITIAN}

Data yang diperoleh dan diteliti yaitu data LPLPO (Laporan Pemakaian dan Lembar Permintaan Obat) Puskesmas se Kabupaten Kuningan dari bulan Januari sampai dengan bulan Desember 2013. Waktu penelitian dilakukan pada bulan Desember 2014 dan Januari 2015.Tempat penelitian dilaksanakan di Gudang Farmasi dan Perbekalan Kabupaten Kuningan.

Metode pengambilan data melalui data primer diperoleh melalui wawancara langsung kepada beberapa petugas pengelola Puskesmas yang datang ke Gudang Farmasi dan petugas di Gudang Farmasi yang bertanggungjawab dalam penerimaan LPLPO Puskesmas untuk 
perbandingan dengan data sekunder yang diperoleh dan data sekunder diperoleh dari data LPLPO Puskesmas yang dilaporkan ke Gudang Farmasi Kabupaten Kuningan serta referensireferensi terkait lainnya yang berhubungan dengan penelitian sebagai perbandingan terhadap data primer yang diperoleh.

\section{HASIL PENELITIAN}

Laporan Pemakian dan Lembar Permintaan Obat (LPLPO) dilaporkan/disampaikan oleh puskesmas ke dinas kesehatan untuk mendapatkan persetujuan dari Kepala Dinas Kesehatan Kabupaten/Kota. Formulir ini dipakai untuk mencatat pemakaian obat pada periode bulan berjalan dan sekaligus untuk permintaan obat bulan berikutnya di puskesmas yang bersangkutan. $^{3,4}$

Pelaporan LPLPO disampaikan ke dinas kesehatan paling lambat tanggal 5 setiap bulannya karena ditingkat kabupaten harus melaksanakan rekapitulasi laporan LPLPO untuk dilaporkan ke tingkat provinsi paling lambat tanggal 10 setiap bulannya. ${ }^{3,4}$ Dari 37 yang puskesmas yang ada di Kabupaten Kuningan hanya 65,2\% (283 puskesmas) saja yang dapat menyerahkan LPLPO ke Dinas Kesehatan sebelum tanggal 5 setiap bulannya, sisanya 34,8\% (161 puskesmas) tergolong puskesmas yang lambat dalam penyerahan LPLPO ke Dinas Kesehatan.

\section{PEMBAHASAN}

\section{Jumlah pemakaian obat analgetika non narkotika sedian sirup}

Jenis obat analgetika non narkotika sedian sirup yang ada di puskesmas terdiri dari Parasetamol sirup dan Ibuprofen sirup. Jumlah pemakaian dalam 1 tahun terdiri dari Parasetamol sirup sebanyak 67.783 botol (95\%) dan Ibuprofen sirup sebanyak 3.446 botol $(5 \%)$.

Parasetamol adalah obat golongan Analgetik Antipiretik turunan Para aminofenol. Sama seperti Aspirin obat ini bekerja dengan menghambat sintesis prostaglandin. Obat ini mempunyai daya antiinflamasi yang sangat lemah sehingga tidak digunakan sebagai antireumatik. Parasetamol menurunkan suhu badan melalui efek langsung terhadap pusatpusat pengatur suhu disusunan saraf pusat, memperbanyak pengeluaran panas badan dengan meningkatkan peredaran darah tepi atau Perifer dan berkeringat. ${ }^{5}$

Ibuprofen adalah turunan asam Propionat yang berhasiat sebagai antiinflamasi, analgetik dan antipiretik obat ini bekerja menghambat sintesis prostaglandin.Obat ini mempunyai efek samping yang lebih sedikit dibanding obat AINS (Anti Inflamasi Non Steroid) lain, tetapi sifat anti inflamasi lebih lemah. ${ }^{5}$

\section{Jumlah pemakaian antibiotika sediaan sirup}

Jenis obat antibiotika sedian sirup yang ada di puskesmas terdiri dari Amoxilin sirup 125 mg, Cotrimoksazol suspensi, dan Cefadroxil sirup $125 \mathrm{mg}$. Jumlah pemakaian dalam 1 tahun terdiri dari Amoxilin sirup $125 \mathrm{mg}$ sebanyak 51.371 botol, Cotrimoksazol suspensi 40.523 botol, Cefadroxil sirup $125 \mathrm{mg} 3.281$ botol.

Amoksisilin bersifat bakterisida dengan bekerja menghambat pembentukan dinding sel bakteri. Obat ini mempunyai kerja spectrum yang lebih luas daripada penisilin G. Obat ini digunakan untuk infeksi yang disebabkan oleh bakteri gram positif dan gram negatif. Selain itu, obat ini juga sangat efektif untuk pengobatan infeksi saluran pernapasan atas, saluran kemih serta peneumonia terutama pada bayi dan anak-anak dibawah umur 5 tahun. ${ }^{5}$

Kotrimoksazol merupakan kombinas dua obat yang terdiri dari Sulfametoksazol dan Trimethoprim. Kontrimoksazol bersifat bakterisida. Obat ini dapat mengobati infeksi yang disebabkan oleh jenis bakteri tertentu. Kombinasi ini selain untuk meningkatkan aktivitas anti 
bakteri juga bertujuan untuk menurunkan toksisitas obat melalui penurunan dosis pengobatan dibandingkan dengan pengobatan dosis tunggal. ${ }^{5}$

Sefadroksil adalah antibiotik sistemik golongan sefalosform untuk pemakaian oral. Sefadroksil bersifat bakterisid dengan jalan menghambat sintesis dinding sel bakteri. Sefadroksil aktif terhada Streptococcus beta-hemolitic, staphylo coccus aureus, Streptococcus pneumoniae, E.Coli, Proteus mirabillis. ${ }^{5}$

\section{Jumlah pemakaian obat diuretika}

Jenis obat diuretika yang ada di puskesmas terdiri dari Furosemide $40 \mathrm{mg}$ tablet dan Hidroklortiazida $25 \mathrm{mg}$ tablet. Jumlah pemakaian dalam 1 tahun terdiri dari Furosemide 40 mg tablet sebanyak 24.481 tablet dan Hidroklortiazida $25 \mathrm{mg}$ tablet sebanyak 75.119 tablet.

Furosemid merupakan diuretik. Obat ini bekerja dengan cara menghambat reabsorbsi cairan pada lengkung henle bagian atas pada tubulus ginjal. Kerja obat terlihat mulai 30-60 menit setelah pemberian oral dan diuresis sempurna dalam 4-6 jam. Furosemid efektif jika dibutuhkan kerja diuresis yang cepat. Seperti misalnya mengurangi udem, udem paru akut akibat gagal jantung kiri, obat ini juga efektif pada pasien yang tidak respon terhadap diuretic tiazid. $^{5}$

Hidroklortiazid (HCT) merupakan diuretic golongan tiazid dengan potensi sedang, yang bekerja dengan cara menghambat reabsorbsi natrium pada baigan awal tubulus ginjal. Mula kerja diuretic ini setelah pemberian oral lebih kurang 1-2 jam, sedangkan masa kerjanya 1224 jam/hari. Obat ini digunakan untuk mengurangi edema akibat gagal jantung. ${ }^{5}$

\section{Jumlah pemakaian obat antidiabetika oral}

Jenis obat antidiabetika oral yang ada di puskesmas terdiri dari Metformin $500 \mathrm{mg}$ tablet dan Glibenklamide $5 \mathrm{mg}$ tablet. Jumlah pemakaian dalam 1 tahun terdiri dari Metformin 500 mg tablet sebanyak 40.125 tablet dan Glibenklamide $5 \mathrm{mg}$ tablet sebanyak 63.402 tablet.

Metformin merupakan obat golongan biguanida yang digunakan untuk penderita diabetes mellitus. Obat ini cara kerjanya berbeda dengan glibenklamide, meskipun memberikan tujuan yang sama yaitu mengontrol kadar glukosa dalam darah. ${ }^{5}$

Selain itu, metformin bekerja dengan cara menghambat terbentuknya glukosa oleh hepar, hepar merupakan organ terbesar tubuh yang dapat menyimpan cadangan glukosa dalam bentuk glikogen. Glikogen ini akan diubah menjadi glukosa bila tubuh membutuhkan asupan glukosa. Untuk proses ini dibutuhkan juga laktat. Dengan dihambatnya proses pembentukan glukosa maka laktat di dalam darah akan meningkat. ${ }^{5}$

Glibenklamid merupakan obat antidiabetik golongn sulfonil urea untuk pengobatan diabates mellitus tipe II. Obat-obat golongan sulfonil urea bekerja dengan cara merangsang sekresi insulin di pangkreas sehingga hanya efektif bila sel beta pangkreas masih dapat berproduksi. $^{5}$

\section{SIMPULAN}

Dari hasil penelitian evaluasi LPLPO Puskesmas se-Kabupaten Kuningan tahun 2013 maka dapat disimpulkan bahwa LPLPO (Laporan Pemakaian dan Lembar Permintaan Obat) merupakan bukti tertulis yang dapat dijadikan sumber data dan mempunyai fungsi sebagai berikut :

1. Bukti Pengeluaran Obat dan BMHP (Bahan Medis Habis Pakai) di UPTD Gudang Farmasi.

2. Bukti Penerimaan Obat dan BMHP di masing-masing puskesmas.

3. Bukti penggunaan obat dan BMHP di masing-masing puskesmas. 
4. Bukti permintaan/pesanan obat dan BMHP dari puskesmas kepada Dinas Kesehatan Kabupaten/kota cq. UPTD Gudang Farmasi.

Bahan data perencanaan kebutuhan obat dengan menggunakan metode konsumsi baik di tingkat puskesmas maupun di tingkat kabupaten/kota.

\section{SARAN}

1. Dinas Kesehatan mengadakan pelatihan manajemen pengelolaan obat bagi petugas pengelola obat puskesmas karena masih adanya beberapa puskesmas yang tidak up to date dalam hal cara pengisian format LPLPO.

2. Sebaiknya sistem administrasi pencatatan dan pelaporan menggunakan software demi untuk mengefektifkan dan mengefisienkan pengelolaan data. Sistem pencatatan dan pelaporan di UPTD Gudang Farmasi maupun di Puskesmas masih menggunakan sistem manual.

3. koreksi serta masukan yang konstruktif sangat saya harapkan demi perbaikan dimasa yang akan datang karena hasil evaluasi LPLPO Puskesmas se-Kabupaten ini masih jauh dari kesempurnaan

\section{DAFTAR PUSTAKA}

1. Departemen Kesehatan RI. Pedoman pengelolaan obat publik dan perbekalan kesehatan. Jakarta: Ditjen Binafar dan Alkes; 2005.

2. Departemen Kesehatan RI. Pedoman teknis pengadaan obat publik dan perbekalan kesehatan. Jakarta: Ditjen Binafar dan Alkes; 2003.

3. Departemen Kesehatan RI,. Pedoman pengelolaan obat publik dan perbekalan kesehatan di Puskesmas. Jakarta:Ditjen Binfar dan Alkes; 2004.

4. Departemen Kesehatan RI. Pedoman pelayanan kesehatan dasar. Jakarta: Ditjen Binkesmas;2001

5. Tjay, TH., Rahardja, K. Obat-obat penting. Cetakan ke-VI. Jakarta : PT.Gramedia; 2007 